FABIO ROMEU CANTON FILHO

\title{
"A VALORAÇÃO DO BEM JURÍdICO PENAL E A CONSTITUIÇÃO FEDERAL DE 1988: A EVOLUÇÃO HISTÓRICA DAS CRIMINALIZAÇÕES NO DIREITO PENAL BRASILEIRO”,
}

\author{
DOUTORADO EM DIREITO
}

ORIENTADOR: PROFESSOR DOUTOR VICENTE GRECO FILHO

FACULDADE DE DIREITO DA UNIVERSIDADE DE SÃO PAULO

SÃO PAULO 


\title{
"A VALORAÇÃO DO BEM JURÍdICO PENAL E A CONSTITUIÇÃO FEDERAL DE 1988: A EVOLUÇÃO HISTÓRICA DAS CRIMINALIZAÇÕES NO DIREITO PENAL BRASILEIRO”,
}

\begin{abstract}
Tese de Doutorado na área de concentração de Direito Penal, sob a orientação do Professor Doutor Vicente Greco Filho, no Curso de Doutorado em Direito, da Universidade de São Paulo, como exigência parcial para obtenção do título de Doutor em Direito.
\end{abstract}

São Paulo 
BANCA EXAMINADORA: 
Dedicatórias:

Aos meus pais,

Dr. Fabio Romeu Canton (in memoriam) e

Thereza Rosati Canton,

À minha mulher e ao meu filho,

Flora Passos Gerevini Canton e

Fabio Gerevini Canton,

inspiradores do mais sublime amor. 
Agradecimentos:

Ao Professor Doutor Vicente Greco Filho, pela amizade, pela orientação e pelos preciosos ensinamentos no curso de pós-graduação da Faculdade de Direito da Universidade de São Paulo.

Ao Professor Doutor Renato de Mello Jorge Silveira, pela amizade e pelo permanente incentivo.

Ao Professor João Daniel Rassi, pela inestimável colaboração para a realização deste trabalho com a disponibilização de sua biblioteca particular.

Ao Professor Diógenes Madeu, pelo apoio de sempre e pelos proveitosos debates aproveitados neste trabalho.

Ao Dr. Alfredo Labriola que me ensinou a arte da advocacia. 


\section{RESUMO}

A valoração do bem jurídico condensa aspectos, sociológicos, axiológicos, ideológicos e normativos, que integram a sua unidade conceitual. O bem jurídico é contextualizado na história da criminalização no direito penal brasileiro e nas suas origens, para que se possa atingir um diagnóstico seguro dos câmbios estruturais e valorativos que reorganizam o sistema punitivo, em face, exatamente, da valoração do bem jurídico, como núcleo atrativo dos valores vigentes na sociedade. Com a eleição do bem juridicamente tutelado é definida a conduta que deverá ser criminalizada e a proporção da pena.

Todos esses pontos atingem o maior grau de condensação na Constituição Federal, que reúne, hodiernamente e na categoria de direitos fundamentais, um elenco significativo de bens jurídicos que devem ser tutelados pelo direito penal, estabelecendo, inclusive, entre eles, uma graduação axiológica, que pode ser medida pelo conteúdo da norma constitucional, que em determinados casos atinge elevado nível de cogência e imperatividade.

Os bens jurídicos não são únicos em relação às normas que os tutelam, mas plúrimos, do que se conclui que mais de um bem jurídico é atingido ao se eleger um como objeto de tutela, surgindo a figura do bem jurídico preponderante.

Para melhor proteger estes direitos, a doutrina busca um consenso a respeito de qual seja um núcleo comum capaz de definir os bens jurídicos constitucionalmente protegidos, do que resulta a possibilidade, inclusive, de concluir a existência de bens jurídicos permanentes a reclamarem a tutela do estado através dos tempos.

Palavras chave: bem jurídico penal - valor - sociedade - risco - constituição criminalização. 


\section{ABSTRACT}

The assessment of a juridical value concentrates sociological, axiological, ideological and legal aspects, which integrate its theoretical unity. The juridical value is mentioned in the history of the criminalization of the Brazilian criminal law and its origins, in order to achieve an accurate diagnosis of the structural and axiological exchanges that reorganize the punitive system, in view, exactly, of the assessment of juridical value as an attractive essence of the effective principles in the society. Through the election of the safeguarded juridical value is defined the conduct that shall be criminalized and the proportion of the penalty.

All these aspects achieves a higher leverage of concentration in the Federal Constitution, which incorporates, nowadays and in the category of the fundamental rights, a significant list of juridical values that shall be safeguarded by the criminal law, inclusive establishing, among them, an axiological graduation that could be measured by the content of the constitutional provision, which in some cases achieve an elevated level of cogency and authority.

The juridical values are not the only ones in relation to the legislation that defend them, but several, from which is concluded that more than one juridical value is achieved when is elected one of them as a safeguarded value, creating the institute of the preponderant juridical value.

In order to enhance the protection of these rights, the doctrine seeks a consensus regarding which would be the universal essence able to define the juridical values constitutionally safeguarded, from which result the possibility, of concluding the existence of permanent juridical values claiming the legal protection in all times.

Keywords: criminal juridical value - value - society - risk - constitution criminalization. 


\section{RIASSUNTO}

L'attribuzione di un valore al bene giuridico condensa aspetti sociologici, assiologici, ideologici e normativi, che sono inerenti alla sua unità concettuale. Il bene giuridico è inserito nel contesto della storia della criminalizzazione nel diritto penale brasiliano e nelle sue origini, permettendo che si possa raggiungere una diagnosi sicura dei cambiamenti strutturali e di valori che riorganizzano il sistema punitivo, in vista esattamente dell'attribuzione di un valore al bene giuridico, visto come nucleo attrattivo dei valori vigenti nella società. Con la scelta del bene giuridicamente tutelato viene definita la condotta che dovrà essere criminalizzata e la proporzione della pena.

Tutti questi punti attingono il maggior grado di concentrazione nella Costituzione Federale Brasiliana, che riunisce nel quotidiano e nella categoria dei diritti fondamentali un elenco significativo di beni giuridici che devono essere tutelati dal diritto penale, stabilendo inoltre tra loro una graduazione assiologica, che può essere misurata attraverso il contenuto della norma costituzionale, che in determinati casi è notevolmente vincolante ed imperativa.

I beni giuridici non sono unici in relazione alle norme che li tutelano, ma plurimi. $\mathrm{Ne}$ deriva che quando se ne sceglie uno come oggetto di tutela, si attingono più beni giuridici, sorgendo così la figura del bene giuridico preponderante.

Per meglio proteggere questi diritti la dottrina cerca un consenso per definire quale sia un nucleo comune che possa definire i beni giuridici costituzionalmente protetti. $\mathrm{Ne}$ deriva inoltre la possibilità di concludere che esistono beni giuridici permanenti, che richiedono attraverso i tempi la tutela dello stato.

Parole chiave: bene giuridico penale - valore - società - rischio - costituzione criminalizzazione. 


\section{SUMÁRIO}

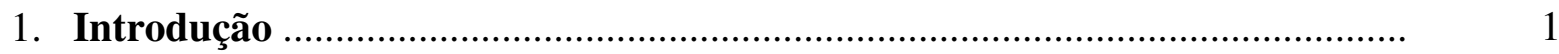

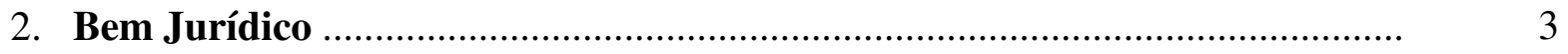

2.1. Evolução do conceito de bem jurídico ....................................................... 6

2.2. Bem jurídico-penal .......................................................................... 15

2.3. Valor e bem jurídico ................................................................................ 22

2.4. O caráter ideológico da escolha do bem jurídico ....................................... 39

2.5. O bem jurídico na sociedade do risco ...................................................... 43

3. A Evolução Histórica das Criminalizações no Direito Penal Brasileiro .......... 56

3.1. O bem jurídico penal nas ordenações do reino ......................................... 56

3.2. O bem jurídico penal nos Códigos Penais brasileiros ................................. 66

3.2.1. O Código Criminal do Império (1830) ….......................................... 66

3.2.2. O Código Penal de 1890 ................................................................... 79

3.2.3. O Código Penal de 1940 ................................................................... 89

3.2.4. O Código Penal de 1969 ...................................................................... 108

3.3. O bem jurídico penal nas Constituições Brasileiras ..................................... 111

3.3.1. A Constituição Federal de 1824 ........................................................ 111

3.3.2. A Constituição Federal de 1891 ....................................................... 114

3.3.3. A Constituição Federal de 1934 ......................................................... 116

3.3.4. A Constituição Federal de 1937 .......................................................... 119

3.3.5. A Constituição Federal de 1946 .......................................................... 123

3.3.6. A Constituição Federal de 1967 ......................................................... 126

3.3.7. A Constituição Federal de 1988 ......................................................... 130 
4.1. Art. $5^{\circ}, \mathrm{X}$ - inviolabilidade da intimidade, da vida privada, da honra e da imagem das pessoas

4.2. Art. $5^{\circ}, \mathrm{XI}-$ inviolabilidade da casa

4.3. Art. $5^{\circ}$, XII - inviolabilidade do sigilo da correspondência, das comunicações telegráficas, de dados e das comunicações telefônicas ...

4.4. Art. $5^{\mathrm{o}}, \mathrm{XXXII}$ - a tutela penal do consumidor

4.5. Art. 5ำ XLI - discriminação atentatória dos direitos e liberdades fundamentais

4.6. Art. $5^{\circ}$, XLII - racismo

4.7. Art. $5^{\circ}$, XLIII - tortura, tráfico ilícito de entorpecentes e drogas afins, terrorismo, crimes hediondos

4.7.1. Tortura

4.7.2. Tráfico ilícito de entorpecentes e drogas afins

4.7.3. Terrorismo

4.7.4. Crimes hediondos

4.8. Art. 5ํㅜ XLIV - criminalização da ação de grupos armados contra a ordem constitucional e o Estado Democrático

4.9. Art. $5^{\circ}$, XLVII - criminalização com previsão de pena de morte

4.9.1. Tipificações do Código Penal Militar

4.10. Art. $7^{\circ}, \mathrm{X}$ - retenção abusiva do salário

4.11. Art. 85 - crime de responsabilidade do Presidente da República ........

4.12. Art. $100, \S 6^{\circ}$ - crime de responsabilidade de Presidente de Tribunal .

4.13. Art. $167, \S 1^{\circ}$ - crime de responsabilidade relativo ao investimento cuja execução ultrapasse um exercício financeiro sem a prévia inclusão no plano plurianual

4.14. Art. 173, $\S 5^{\mathrm{o}}$ - responsabilidade da pessoa jurídica nos atos praticados contra a ordem econômica e financeira e contra a economia popular

4.15. Art. 225, $\S 3^{0}$ - lesão ao meio ambiente

4.16. Art. $227, \S 4^{\circ}-$ o abuso, a violência e a exploração sexual da criança e do adolescente 
5. Situação do Bem Jurídico

5.1. Da Lei à Constitucionalização

5.2. Núcleo Comum do Bem Jurídico

5.3. Bens Jurídicos Permanentes

6. Conclusões 